\title{
Arbor
}

\section{Secuencias, conformación, información: bioquímicos y biólogos moleculares en los años 50*}

Soraya de Chadarevian

Arbor CLVI, 614 (Febrero 1997) 15-44 pp.

Los bioquímicos han reivindicado en numerosas ocasiones su lugar en la historia de la biología molecular de la que se sintieron injustamente excluidos ${ }^{1}$. Los historiadores han analizado la discusión entre los bioquímicos y los biólogos moleculares en cuanto a las demandas intelectuales y en términos de conflicto de autoridad disciplinar ${ }^{2}$. En este artículo propongo una aproximación a las disputadas reclamaciones de los bioquímicos y los biólogos moleculares conectando el análisis de las demandas disciplinarias con el de las herramientas y prácticas que se usaron para argumentar la distinción entre los dos campos. Sugiero que la secuenciación de proteínas es un caso particularmente fructífero para tal enfoque.

Los bioquímicos interesados en la estructura y función de las proteínas fueron los pioneros en la secuenciación

* "Sequences, Conformation, Information. Biochemists and Molecular Biologists in the 1950s", Journal of the History of Biology (Fall 1996). Copyright: Kluwer Academic Publishers. Traducción: Carolina Moreno. 
como paso previo a su síntesis. Los biólogos moleculares, por su parte, coinciden en afirmar la importancia del trabajo pionero de Fred Sanger en la secuenciación de proteínas por sus investigaciones genética y estructural ${ }^{3}$. La información genética llegó a ser definida como especificación de la secuencia de aminoácidos de las proteínas. Esta misma noción, sin embargo, también fue usada por los biólogos moleculares para marcar la distancia entre su campo y el de los bioquímicos ${ }^{4}$. Se ha sugerido que una investigación de la reacción de los bioquímicos ante el trabajo de secuenciación de Sanger ayudaría a establecer la actitud de la comunidad bioquímica ante el concepto de información ${ }^{5}$.

A continuación, relacionaré el análisis detallado del desarrollo y de los usos de la secuenciación de proteínas por los bioquímicos y por los biólogos moleculares con las negociaciones que acompañaron a la construcción del nuevo campo de la biología molecular. Mi enfoque trata sobre los desarrollos en Cambridge (Inglaterra), esto es, sobre el trabajo de Sanger en el departamento de Bioquímica y sobre la forma en que su trabajo de secuenciación fue adoptado y él mismo aceptado por los cristalógrafos de proteínas y. por los genetistas moleculares que trabajaban para el $\mathrm{Me}$ dical Research Council Unit for the Study of the Molecular Structure of Biological Systems. Este grupo, encabezado por Max Perutz e integrado, entre otros, por John Kendrew, Francis Crick, Vernon Ingram y, posteriormente, Sydney Brenner, estaba trabajando en el Cavendish, departamento de Física de Cambridge. Era un grupo pequeño de investigadores respaldados por el poderoso profesor de física, Lawrence Bragg, y por el MRC, pero sin una ubicación clara en el paisaje disciplinario de la. Universidad. Como Perutz solía decir, él trabajaba como químico en un departamento de física sobre un problema biológico ${ }^{6}$. A finales de los 50 , este grupo, junto con el grupo de Sanger, entró en negociaciones con el MRC y la Universidad para la construcción de un laboratorio de Biología Molecular. Los dos grupos constituyeron el núcleo del laboratorio en los años 60 y 70, llegando a ser lo que Latour ha llamado un "punto obligatorio de paso" dentro del nuevo campo de la biología molecular ${ }^{7}$.

Las negociaciones políticas y las reuniones de trabajo se dieron al mismo tiempo, así como la puesta en marcha 
Secuencias, conformación, información...

del Journal of Molecular Biology en la que, de nuevo, John Kendrew de la MRC-Unit estuvo principalmente involucrado. Explicaré cómo se iniciaron las colaboraciones en el laboratorio entre los bioquímicos y los que serían llamados biólogos moleculares y analizaré cómo estas redes de colaboración se usaron y se transformaron a través de desarrollos institucionales y disciplinares impulsados por las mismas personas.

\section{Secuenciación de proteínas}

En un reciente ensayo autobiográfico en el Annual Review of Biochemistry, Fred Sanger se propuso desmentir lo que consideraba un relato romántico de sus logros en la química de proteínas. Insistió en que el retrato de él sólo resuelto a determinar la estructura de la insulina en contra del criterio de sus colegas, quienes creían que las proteínas eran una mezcla amorfa mal definida que no podría ser estudiada por métodos químicos, era completamente erróneo. Él sostuvo que todos los bioquímicos con los que estaba asociado, cuando era un joven investigador, siguieron a Emil Fischer y a su escuela, que dependía enteramente de los estudios químicos de las proteínas. En cualquier caso, Sanger observó que se aplicaba demasiado la estequiometría a las proteínas en aquellos días ${ }^{8}$.

Sanger se formó como bioquímico en Cambridge y se doctoró por su trabajo sobre el metabolismo de la lisina en 1943. En aquellos años, la mayoría de los investigadores fueron movilizados para colaborar en la guerra. Sin embargo, la investigación sobre proteínas del departamento de Bioquímica, en Cambridge, cayó bajo la investigación en nutrición y, por tanto, la investigación pudo continuar durante la guerra ${ }^{9}$. Sanger comenzó su trabajo sobre la insulina con Charles Chibnall quien, en 1943, se había trasladado del London Imperial College, en Londres, a Cambridge como sucesor de Gowland Hopkins como jefe del departamento de Bioquímica. Chibnall sugirió a Sanger que obtuviera estimación cuantitativa e identificara los aminoácidos con un grupo amino libre en alfa en la insulina. La elección de este tema de investigación estaba íntimamente conectada 
con el trabajo de investigación del grupo de químicos de proteínas que Chibnall, tras su traslado, y casi de una sola vez, reunió en Cambridge ${ }^{10}$.

En sus investigaciones sobre la estructura química de las proteínas, Chibnall y sus colaboradores encontraron que el número de grupos amino libres en alfa en la insulina era apreciablemente mayor que el contabilizado por su contenido en lisina. Estos resultados sugirieron que el exceso se debía a los grupos amino libres en alfa, indicando que las cadenas de la molécula de la insulina eran relativamente cortas. De hecho, en su destacada Conferencia Bakerian en la Royal Society, en 1942, Chibnall había sugerido que la insulina consistía en 18 cadenas de péptidos de composición diferente ${ }^{11}$.

Las cadenas cortas postuladas por Chibnall hicieron a la insulina particularmente apropiada para estudios químicos. Además, la insulina estaba disponible comercialmente. Esto, más que su importancia médica, atrajo a los investigadores de proteínas. La insulina, sin embargo, no hubiera estado presente si no hubiera sido por su uso terapéutico y su elección como herramienta de investigación abrió la posibilidad de poderosas alianzas con el sector médico y farmacéutico. Por este motivo, apenas sorprende que el trabajo posterior de Chibnall sobre la estructura química de la insulina fuera apoyado por una subvención de Eli Lilly, la compañía que entonces dominaba el mercado de la insulina ${ }^{12}$.

Los diferentes métodos para la determinación del grupo final de las proteínas 'se describieron en la literatura. Un artículo de revisión de 1945 enumeró dos docenas de ellos ${ }^{13}$. Pero ninguno produjo resultados fiables. Probablemente fue de nuevo Chibnall quien insinuó a Sanger usar fluordinitrobenceno como reactivo ${ }^{14}$. Los químicos orgánicos tendían a apartarse de los flúorderivados por su toxicidad, pero en la investigación de gases durante la guerra fueron sintetizados por esa misma razón. Chibnall se enteró de que Bernhard Charles Saunders, un profesor del departamento de Química, disponía de ese compuesto.

Como Chibnall previó, Sanger descubrió que el fluordinitrobenceno reaccionaba en condiciones mucho más suaves que las empleadas generalmente con compuestos del 
Secuencias, conformación, información...

cloro. Esto era un requisito esencial, ya que las altas temperaturas provocaban la ruptura de la cadena de la proteína y había ofrecido resultados poco fiables en el pasado. Además, los dinitrofenil-aminoácidos eran más estables en la hidrólisis en caliente que el enlace peptídico y de color amarillo brillante en solución. Por lo tanto, pudieron someterse al nuevo método de separación cromatográfica de Martin y Synge. Esta técnica ya había sido usada en el grupo de Chibnall por Tristam para determinar la composición de los aminoácidos de la insulina. Su trabajo y su experiencia fueron pues de doble utilidad para Sanger.

Un breve vistazo al desarrollo de la nueva técnica de fraccionamiento añade una faceta adicional al contexto de la investigación en proteínas en las décadas de los años 30 y $40^{15}$. Ambos, Archer Martin y Richard Synge comenzaron sus carreras en Cambridge. Martin trabajaba en el Dunn Nutritional Lab, donde desarrolló una máquina de extracción fraccional contracorriente para la vitamina $\mathrm{E}$ que atrajo mucha atención. Synge trabajaba en glicoproteínas con Pirie en el departamento de Bioquímica. Ambos continuaron su trabajo bajo la égida de la International Wool Secretariat. Esta secretaría fue fundada por productores de lana de Australia, Nueva Zelanda y Suráfrica por razones publicitarias y de investigación; estaban entonces preocupados por la caída del mercado y por la llegada de fibras sintéticas que resultaron eficaces sustitutos de la lana. Martin se trasladó al Wool Industries Research Association en Leeds para estudiar el enfurtido de la lana y desarrollar métodos analíticos. Synge, que posteriormente se unió a Martin en Leeds, tenía una beca del Wool Secretariat para estudiar la composición de los aminoácidos de la lana. Trabajando juntos en Leeds, y al mismo tiempo experimentando con diferentes técnicas de fraccionamiento, Martin y Synge descubrieron que los aminoácidos acetílicos podían ser separados mejor por combinación de técnicas cromatográficas y de extracción en contracorriente. Desarrollaron la nueva partición cromatográfica aplicándola a sus problemas y clarificando su modo de acción teóricamente ${ }^{16}$. Como Martin señaló después, otros investigadores desarrollaron técnicas similares por aquel entonces pero, al no tener problemas que solucionar, sus trabajos pasaron inadvertidos ${ }^{17}$. Entre 
los que siguieron el desarrollo del trabajo de Synge y Martin, y con particular interés, se encontraba Chibnall ${ }^{18}$.

Para Sanger la posibilidad de aprovechar técnicas y conocimientos de sus colegas no quería decir que su proyecto fuera fácil. Tardó dos años en optimizar el método de fluordinitrobenceno para la determinación del grupo final. Su primer artículo fue publicado en 1945. Sus resultados sugerían que la insulina estaba compuesta de dos cadenas con fenilalanina y glicina como aminoácidos $\mathrm{N}$-terminales, y con cadenas unidas por puentes disulfuro ${ }^{19}$. Mientras la investigación para desarrollar métodos alternativos no cesaba, los métodos de determinación del grupo final de Sanger representaron una mejora significativa de los anteriores, y fueron extensamente utilizados en aquel momento. Llegó a ser una importante herramienta bioquímica para la estimación del número y longitud de las cadenas peptídicas en proteínas. También fue usado como prueba de pureza y para la identificación de proteínas individuales.

¿Cómo hicieron Sanger y sus colaboradores para ir de la determinación del grupo final a la secuenciación de la insulina? En una declaración posterior sobre su artículo de 1945, Sanger insinuó que ya se había producido un cambio en el curso de la química de las proteínas desde el interés ańalítico a otro sobre la ordenación de los aminoácidos en las cadenas ${ }^{20}$. Esto, sin embargo, podría parecer así visto en retrospectiva. De hecho, en otra ocasión Sanger destacó su artículo de 1949, en el que publicó la secuencia de cuatro de los cinco residuos $\mathrm{N}$-terminales de las dos cadenas de la insulina, como el logro más importante. Este trabajo también se debió a su propia iniciativa ${ }^{21}$. Aun así, en conversación, Sanger insistía en que pensar sobre la secuenciación no era un gran hallazgo intelectual. Desde el trabajo pionero de Fischer sobre estructura de proteínas, los químicos de proteínas trabajaron para lograr ese objetivo. Fue algo claramente importante, y si hubiera sido posible, uno obviamente lo hubiera hecho ${ }^{22}$. Llegó a él optimizando y explotando técnicas empleadas para la determinación de los grupos terminales. El auténtico adelanto, según Sanger, fue el desarrollo de las nuevas técnicas de fraccionamiento. De hecho, Synge y Martin, usando su técnica, publicaron la secuencia del pentapéptido Gramicidina S en 1948, un 
Secuencias, conformación, información...

año antes de que Sanger presentara su primera parte de secuencia $^{23}$.

En las escasas observaciones generales que encontramos en sus artículos publicados, Sanger destacaba que su interés por la secuenciación estaba en introducirse en el mecanismo de reacción de la insulina, que constituía un modelo de hormonas proteínicas y enzimas. Situaba así su trabajo en la tradición de investigación en la cual la estructura, en este caso el orden de aminoácidos en péptidos, era clave para comprender la función. Desde Fischer, ésta fue una línea central de investigación en proteínas, en laboratorios químicos $\mathrm{y}$ bioquímicos.

Cuando la secuencia completa de la insulina no proporcionó pista alguna sobre su función, Sanger persistió en su búsqueda de explorar nuevas maneras y usos de la secuenciación. Un objetivo fue identificar el centro activo de la insulina determinando y comparando las secuencias de proteínas homólogas de especies diferentes. Otro acceso utilizado consistía en marcar el centro activo y determinar la secuencia a su alrededor. Experimentando con marcajes radiactivos, Sanger y sus colaboradores desarrollaron técnicas que permitieron deducir la secuencia de péptidos sin llevar a cabo un análisis de aminoácidos ${ }^{24}$.

Otros investigadores permanecían activos en este terreno. El método de secuenciación de Sanger fue reemplazado muy pronto por un procedimiento basado en la degradación por pasos de la cadena de polipéptidos, desarrollada por Pehr Edman en la Universidad de Lund en Suecia ${ }^{25}$. Este procedimiento, combinado con métodos automatizados de análisis cuantitativo de aminoácidos desarrollado por Stein y Moore en el Instituto Rockefeller de Nueva York, permitió emprender el análisis de secuencias de proteínas más grandes ${ }^{26}$.

La secuenciación de proteínas llegó ser una herramienta analítica estándar. En un artículo de revisión de finales de los 60, Brian Hartley, que trabajaba en el grupo de Sanger, documentó un crecimiento exponencial de la actividad de secuenciación, relacionado tanto con la velocidad como con el volumen de trabajo ${ }^{27}$. ¿Cúal era el significado de esta "tremenda industria"?, inquirió Hartley; él mismo pasó de los clásicos estudios cinéticos sobre la función de 
los enzimas a la secuenciación a comienzos de los años 50. De acuerdo con su relato, en aquel tiempo llegó a convencerse de que para saber cómo funcionaban los enzimas había que conocer su estructura, por ejemplo, su secuencia de aminoácidos. Nuevas técnicas abrieron el camino ${ }^{28}$. De este modo, el caso del propio Hartley confirma que para los bioquímicos la secuencia representaba la fórmula estructural de las proteínas. Por tanto, cabía esperar que ofreciera pistas sobre los mecanismos de reacción de enzimas y hormonas proteínicas ${ }^{29}$. Además, el conocimiento sobre el orden de los aminoácidos de las proteínas permitiría a los químicos orgánicos aventurarse en la síntesis de las proteínas ${ }^{30}$.

El trabajo de secuenciación de Sanger, sin embargo, fue también expuesto a nuevos usos. En Cambridge, despertó muy tempranamente el interés de los investigadores que trabajaban en la estructura tridimensional de las proteínas y en el control genético de su síntesis, en la MRC-Unit del Cavendish. Un estudio minucioso de las interacciones entre estos diferentes grupos de investigadores ofrece datos interesantes sobre la historia de los inicios de la biología molecular en Cambridge, y arroja nueva luz sobre la controvertida relación entre bioquímicos y biólogos moleculares.

\section{Arquitectura de las proteínas}

En 1955, año en el que Sanger publicó por primera vez la secuencia completa de la insulina, John Kendrew, de la MRC-Unit en Cambridge, que estaba trabajando en la interpretación de los modelos de difracción de rayos $\mathrm{X}$ de la mioglobina (la proteína portadora del oxígeno en los músculos), «buscó por todo el mundo", según sus propias palabras, a alguien que llevase a cabo la determinación de la secuencia completa de aminoácidos de la proteína ${ }^{31}$. En aquel momento, un problema decisivo sobre el análisis de los rayos $\mathrm{X}$ de las proteínas, el llamado "problema de fases", fue solucionado ${ }^{32}$. Kendrew y sus colaboradores tuvieron éxito desarrollando cristales a partir de la mioglobina del esperma de cachalote, pero seguían intentando ligar átomos pesados a las moléculas e identificar sus posiciones ${ }^{33}$. 
Secuencias, conformación, información...

Los datos de los rayos $\mathrm{X}$ de tales compuestos eran necesarios para interpretar las imágenes de difracción. El primer objetivo era mostrar la imagen de rayos $\mathrm{X}$ a una resolución que, por primera vez, mostraría la estructura general de una proteína globular y, posiblemente, la configuración de la cadena de aminoácidos en la molécula. Desde ahí, había un largo camino hasta la resolución atómica de la estructura de la proteína. Buscando la colaboración de los bioquímicos, Kendrew habría podido sacar buen partido a sus recursos. Como sugeriré más adelante, sin embargo, estaba haciendo frente al desafío que representaba el reciente éxito en la secuenciación de proteínas.

En la década de los 30 , cuando las esperanzas y las expectativas sobre una comprensión de la estructura y de la función de las proteínas eran grandes, cristalógrafos y químicos de proteínas fueron parte de una red activa. John Desmond Bernal quien, en 1934, junto con Dorothy Crowfoot tomó la primera imagen de rayos $\mathrm{X}$ de una proteína globular, previó la creación de un "departamento de proteínas", en el que los datos sobre las mismas fueran reunidos y sintetizados ${ }^{34}$. En la década siguiente, sin embargo, varios modelos de estructura de proteínas, basados en datos cristalográficos y químicos, fueron desechados y, para finales de los años 40, las expectativas dieron lugar a una gran desilusión. La cristalografía de proteínas y la química de proteínas parecían ser dos maneras igualmente formidables de comprender la función de las proteínas. En particular los bioquímicos llegaron a desconfiar de los modelos cristalográficos que se sugerían y se rechazaban.

Fue una tarea ardua para Kendrew convencer a alguien para que llevase a cabo el trabajo de secuenciación de la mioglobina. Se dirigió a Sanger, que estaba trabajando en el departamento adyacente de Bioquímica, pero nadie de su grupo estaba preparado para embarcarse en el proyecto ${ }^{35}$. Finalmente dirigió su petición a William Stein y Stanford Moore del Instituto Rockefeller de Nueva York. Había contacto directo entre el laboratorio de Nueva York y el grupo de Sanger. De hecho, en 1951, Moore visitó Cambridge y, durante seis meses, compartió mesa con Sanger. A mediados de los 50, sin embargo, los dos investigadores del Rockefeller perfeccionaron el método original de secuenciación de Sanger 
para su trabajo sobre la ribonucleasa. Más importante aún, habían desarrollado un analizador automático de aminoácidos que producía datos cuantitativos y facilitaba el trabajo enormemente ${ }^{36}$.

La carta de Kendrew a Stein y Moore ofrece una visión importante de los motivos que había detrás de su traslado, y sobre la forma de la que intentó negociar el trato. Empezaba directamente: "Esto es una carta francamente propagandista sugiriendo que quizás sea de su interés $-y$ seguramente sería ventajoso para mí- si ustedes pudieran ser convencidos para llevar a cabo la determinación de la secuencia de los aminoácidos de la mioglobina" ${ }^{37}$. Kendrew explicaba que se sentía con ánimo de pensar que sus destinatarios pudieran estar interesados en su proposición debido a una observación de Moore en su última visita a Cambridge, ya que querían obtener las secuencias de forma rutinaria. Kendrew presentó una larga lista de motivos por los que la mioglobina sería la "proteína de ensayo" perfecta. Cambridge - sugirió- podría aportar al laboratorio de Nueva York grandes cantidades de material purificado. La molécula era comparativamente pequeña y sería la primera proteína con un grupo prostético en ser secuenciada. Nadie más estaba trabajando en la secuencia, pero Chibnall prometió determinar la composición completa de aminoácidos. Sin embargo, el análisis de rayos $\mathrm{X}$ de la mioglobina estaba en marcha. La mioglobina sería, de este modo, el primer caso por el que pudieran ser combinadas aproximaciones físicas y químicas para la determinación de la estructura.

En ese momento, Kendrew estaba preparado para admitir una debilidad principal de la aproximación cristalográfica. Esta debilidad, me gustaría argumentar, se debía a los recientes logros en la secuenciación de proteínas. Tras presentar el progreso en el análisis de rayos $\mathrm{X}$ de las proteínas en términos bastante entusiastas, supuso que por el momento no se podía confiar en lograr identificar las cadenas laterales individuales. En corchetes añadía: «iNi tampoco estamos de acuerdo con ciertos grupos que trabajan en este campo que pretenden resolver la estructura completa de una proteína, átomo a átomo, en unos años, sin ninguna ayuda de los químicos!» ${ }^{38}$. Esto significaba que el trabajo 
Secuencias, conformación, información...

de secuenciación era un "complemento esencial" ${ }^{39}$ para el programa de rayos $\mathrm{X}$.

La debilidad de los métodos físicos de determinación estructural aguantó frente al "poder de los estudios de secuenciación de dar información sobre la arquitectura" que Kendrew mencionaba en la misma carta. Se refería al trabajo reciente de dos investigadores que, usando los datos de la secuencia de la insulina de Sanger, construyeron un modelo tridimensional bastante restrictivo de la molécula, que se prestaba a una correlación inmediata con los datos de rayos $\mathrm{X}^{40}$.

Kendrew señaló repetidamente la posiblidad de que la cristalografía de rayos $\mathrm{X}$ podría quedar obsoleta. También, en su conferencia Nobel en 1962, aludió a las increíbles posibilidades del trabajo de secuenciación. La visión de que el material hereditario determinaba sólo la secuencia de aminoácidos de las proteínas le sugirió que podría predecirse la estructura tridimensional de una proteína solamente con el conocimiento de su secuencia de aminoácidos ${ }^{41}$. Según Kendrew, ese día no llegaría pronto, pero cuando llegara, los cristalógrafos de rayos $\mathrm{X}$ podrían acabar en la calle. En esa ocasión añadió: "quizás con una cierta sensación de alivio" ${ }^{42}$. Su estrategia a mediados de los 50 , sin embargo, era la de ganarse a los secuenciadores de proteínas para una causa común.

Concluyendo su carta a Stein y Moore, Kendrew mostró todas sus cartas. "Desde mi punto de vista" - escribió«apreciarán que es de vital importancia convencer a alguien para que lleve a cabo la secuenciación de la mioglobina". Más estratégicamente añadió: "verdaderamente creo que la mejor y única aproximación práctica para completar la determinación de la estructura es la combinación de métodos químicos y de rayos $\mathrm{X}$ aplicados a la misma proteína" ${ }^{43}$.

Stein y Moore contestaron cautelosamente, pero no negativamente, a la "importante carta" ${ }^{44}$ de Kendrew. A ella siguió una segunda carta de Kendrew, sugiriendo la manera de conseguir personal y dinero para su proyecto ${ }^{45}$. Finalmente, un nuevo programa de posgrado para estudiantes de la Fundación Rockefeller proporcionó una subvención al laboratorio de Nueva York y un posible candidato para el proyecto ${ }^{46}$. Allen Edmunson empezó el proyecto de se- 
cuenciación en los Estados Unidos. Después de resultados preliminares que sirvieron para su tesis doctoral, en octubre de 1960 se unió a la MRC-Unit en Cambridge para continuar el trabajo ${ }^{47}$.

Mientras tanto, en 1957, Kendrew y sus colaboradores presentaron un modelo tridimensional de la mioglobina basado en la difracción de rayos $\mathrm{X}$ con una resolución de 6 Angstrom ${ }^{48}$. Era la primera estructura de proteína globular resuelta. En la construcción del modelo habían supuesto que consistía en una cadena individual de aminoácidos. Esta era la hipótesis más simple basada en la determinación bioquímica de que la mioglobina tenía un solo grupo amino terminal. Esta parte de la información era clave para interpretar la estructura de la molécula ya que, con esa resolución, la cadena no podía seguirse a través de los codos donde perdía su ajustada configuración. Un resultado importante del análisis fue que los datos de los rayos $\mathrm{X}$ eran verdaderamente compatibles con una sola cadena continua, aunque hubiera al menos dos maneras alternativas de trazarla a través de la molécula. Según Kendrew, los dos rasgos más destacados de la molécula eran su complejidad y su falta de simetría. "Carecía totalmente de la clase de regularidades que uno anticipa instintivamente", y era "más complicada que lo predicho por cualquier teoría sobre estructuras de proteínas" ${ }^{49}$. Un miembro del MRC, que vio el modelo, lo comparó con un «modelo anatómico de vísceras abdominales». La cadena de polipéptidos era "como intestinos enrollados complicadamente alrededor de un pequeño objeto rojo que representaba la parte hemo de la molécula" ${ }^{50}$.

Después de su primer triunfo, Kendrew y sus colaboradores decidieron superar los límites de su trabajo y obtener una resolución de 2 Angstrom del modelo de difracción de la mioglobina. Este paso implicaba medir y procesar alrededor de un cuarto de millón de reflexiones, tarea que hubiese sido imposible sin la ayuda de un ordenador de alta velocidad. Kendrew anticipó el uso de ordenadores para computaciones cristalográficas. Como ha dicho Maurice Wilkes, director del Mathematic Lab en Cambridge, las computaciones hechas por los cristalógrafos de proteínas en Cambridge en la década de los 50 no eran, ni mucho menos, 
Secuencias, conformación, información...

simples aplicaciones. Por aquel entonces, representaban logros pioneros considerados de gran interés por los especialistas en ordenadores ${ }^{51}$. En aquel momento, los programas diseñados por los cristalógrafos para sus computaciones llegaron a ser tan complejos que se usaban para probar las máquinas.

Técnicas de interpretación más refinadas permitieron ver más detalles en el mapa de densidad electrónica de 2 Angstrom de resolución que en el precedente. Estudiando cuidadosamente las agrupaciones de densidad proyectadas en los intervalos adecuados de la cadena de polipéptidos, Kendrew y sus colaboradores eran, a menudo, capaces de identificar aminoácidos que constituían la espina dorsal. La gran cantidad inesperada de hélice alfa presente en la mioglobina facilitó esta tarea. Correlacionando los resultados con los datos proporcionados por el trabajo de secuenciación de Edmundson, que entonces tenía algunas dificultades, se pudo formular una secuencia orientativa de aminoácidos. En el artículo en el que se presentó el trabajo de rayos $\mathrm{X}$, una tabla comparaba los datos cristalográficos y bioquímicos minuciosamente, indicando el grado de confianza de cada identificación y las discrepancias de los dos grupos de datos ${ }^{52}$. En este punto, Kendrew insistió en la confirmación independiente proporcionada por los dos métodos. De hecho, el trabajo de secuenciación de Edmundson fue publicado como un artículo aparte, aunque adjunto ${ }^{53}$. Aun así, el trabajo implicaba la producción de datos comparables y resultados concordantes. Este trabajo y su representación en una tabla combinando y correlacionando evidencias de las dos aproximaciones, habla por sí solo del grado en el que los bioquímicos de proteínas y los cristalógrafos habían llegado a modelar mutuamente su trabajo.

La corriente de investigadores, de cristales, de secuencias y de modelos iniciados por la colaboración entre Kendrew y Edmundson resituó el trabajo de químicos y cristalógrafos de proteínas primero a escala local y, a través de los canales usuales de amplificación, también a mayor escala. Explicaré los movimientos institucionales y disciplinares que acompañaron estos desarrollos en Cambridge posteriormente, pero primero consideraré cómo los genetistas moleculares 
que trabajaban en la MRC-Unit aceptaron el trabajo de secuenciación de Sanger.

\section{La hipótesis de la secuencia}

La determinación de secuencias de la insulina de Sanger confirmó que las proteínas consistían en cadenas de aminoácidos cuya secuencia era específica para cada proteína. Este trabajo tuvo un impacto decisivo en las primeras especulaciones sobre el código genético de George Gamow, Crick, Brenner y los otros miembros del RNA-tie Club ${ }^{54}$. Junto a la evidencia, basada principalmente en el mapa de mutaciones a escala de Seymour Benzer sobre la región r-II del bacteriófago T4, de que los genes estaban compuestos de muchas partes dispuestas en orden lineal fue posible formular la "hipótesis de la secuencia». Esta hipótesis asumía que «la especificidad de un fragmento de ácido.nucleico está expresada únicamente por la secuencia de sus bases, y que esta secuencia es un (simple) código para la secuencia de aminoácidos de una proteína en particular" ${ }^{55}$. El trabajo de secuenciación de Sanger no sólo permitió formular esta hipótesis. También proporcionó las primeras herramientas experimentales para probarla. De datos publicados de secuencias de proteínas y análisis relacionados, Brenner dedujo también que era imposible un código superpuesto ${ }^{56}$.

Crick recalcó que el paso decisivo en sus especulaciones sobre el código fue la suposición de que el plegamiento de la proteína se derivaba de la secuencia de aminoácidos. Esto era una suposición atrevida, ya que, en 1957, Crick aún pensaba en algunas posibles excepciones, especialmente considerando las gamma-globulinas y los enzimas adaptables. Fue adoptada, si no por otras razones, sobre bases heurísticas. En su famosa conferencia sobre la síntesis de las proteínas que Crick dio ante la Society for Experimental Biology en 1957, admitió francamente: "Nuestra desventaja básica por el momento es que no tenemos una técnica precisa y fácil con la que estudiar la manera en la que las proteínas se pliegan, mientras que por lo menos podemos hacer algún planteamiento experimental para determinar la secuencia de aminoácidos. Por esta razón, y no por otra, ignoraré el 
Secuencias, conformación, información...

plegamiento en lo siguiente y me concentraré en la determinación de las secuencias" ${ }^{57}$.

En la misma conferencia, Crick también especificó lo que él entendía por «información", alrededor de lo que centró su discusión sobre la síntesis de proteínas. Según Crick, información significaba "la determinación precisa de la secuencia, de bases en el ácido nucleico o de residuos de aminoácidos en proteínas» ${ }^{58}$. Esta definición fue dada en el contexto de "Dogma Central" que, en este caso, fue explícitamente formulado por primera vez. Enunciaba que "una vez que la "información" pasa a la proteína no puede volver a salir. Más detalladamente, la transferencia de información de ácido nucleico a ácido nucleico, o de ácido nucleico a proteína puede ser posible, pero la transferencia de proteína a proteína, o de proteína a ácido nucleico es imposible" ${ }^{59}$. Así, solamente para Crick y para aquellos pocos que entonces pensaron en la biosíntesis de proteínas en términos de "flujo de información" y, de este modo, en términos genéticos, secuencia significó «información" ${ }^{60}$. Para definir lo que ellos comprendieron como "información", sin embargo, tuvieron que recurrir a la noción bioquímica de una secuencia de bases.

A pesar de ello, Crick mantuvo en su conferencia que la cuestión sobre la transferencia de información de ácido nucleico a proteína podía ser examinada bastante independientemente de los pasos bioquímicos implicados. Declaró también que el problema apelaba, en su mayor parte, a "aquéllos con una formación en las ciencias más sofisticadas" mientras que "la mayoría de los bioquímicos, a pesar de estar algo fascinados (por ello), sentían aversión por argumentos de esta clase" ${ }^{61}$. Incluso si usó técnicas y resultados de las prácticas bioquímicas, él y otros después de él utilizaban así el concepto de información para delimitar la distancia entre bioquímica y lo que vino a llamarse genética molecular ${ }^{62}$. Watson y Crick usaron el término por primera vez, pero solamente una vez y no de forma sistemática, en su segundo artículo en Nature en 1953, donde se extendían en las implicaciones genéticas de la estructura del $\mathrm{ADN}^{63}$. Mientras siendo realmente conscientes de los usos técnicos del término, y apoyándose en él para obtener legitimidad, lo emplearon en un sentido coloquial. La imagen 
que Crick tenía en la mente era aparentemente la de la transmisión de información en código Morse por telégrafo; de aquí también la unidireccionalidad del proceso ${ }^{64}$. El concepto de información secuencial anotado en forma de un código de letras, quiero sugerir, fue también fundamental para metáforas como transcripción o translación, que más tarde abundaron en la explicación del proceso de biosíntesis de proteínas.

Antes del ensayo de la hipótesis de la secuencia, era necesario demostrar que un único mutante alteraba la secuencia de aminoácidos de la proteína que codificaba. Este paso no implicaba necesariamente secuenciación ya que hubiera sido suficiente para demostrar que la composición de la proteína estaba afectada por una mutación heredada de forma mendeliana. Crick junto con Vernon Ingram, un químico de proteínas que se unió al MRC-Unit en Cambridge en 1951, decidió atacar el problema estudiando la lisozima en la clara de huevos de gallinas y en las lágrimas humanas. Pero su búsqueda de mutantes no tuvo éxito ${ }^{65}$. Sin embargo, la evidencia de que los genes codificaban exclusivamente la secuencia de aminoácidos llegó de otros experimentos efectuados en el mismo laboratorio.

El anuncio de Linus Pauling y Harvey Itano, en 1949, de que la hemoglobina de una persona con anemia de células falciformes era electroforéticamente diferente de la hemoglobina normal atrajo el interés de Max Perutz, que incluyó la hemoglobina de células falciformes en sus estudios cristalográficos. Los abastecimientos de la proteína eran muy escasos pero Tony Allison, que había realizado unos estudios cristalográficos en la MRC-Unit en Cambridge, dejó algunas muestras al marcharse. Se sabía que la anemia de células falciformes se heredaba de forma recesiva. Estudios anteriores cromatográficos realizados en el laboratorio de Pauling no mostraron una diferencia definitiva en la composición de la hemoglobina de células normales y de células falciformes. La hemoglobina anormal aún podía ser considerada como un caso de ensayo para el problema de Crick e Ingram. Refinando las técnicas de Sanger, Ingram logró verdaderamente esclarecer la diferencia entre las dos hemoglobinas por un único aminoácido ${ }^{66}$. Ésta era la primera evidencia por la cual demostró que un defecto heredado 
Secuencias, conformación, información...

estaba de hecho establecido en la secuencia de aminoácidos de la proteína. Según Crick, fue el trabajo de Ingram lo que más avivó el interés de los bioquímicos de proteínas por la genética ${ }^{67}$.

Después de este primer logro, Crick, Brenner e Ingram, junto con Benzer y George Streisinger, que se reunieron en Cambridge en 1957, intentaron demostrar que el gen, y la proteína que codificaba, eran colineales; es decir, que el orden de mutaciones en un gen se alineaban con el orden de cambios en la secuencia de aminoácidos de la proteína correspondiente. Intentaron usar los mutantes de la región r-II del bacteriófago T4, que había sido finalmente cartografiada por Benzer, como un caso de ensayo. Pero Benzer fracasó al no poder aislar la proteína, y el grupo empezó a usar los mutantes de Streisinger que afectaban a las fibras de la cola del bacteriófago T2 en sus puntas ${ }^{68}$.

Curiosamente, Crick y Brenner no se reprimieron a la hora de utilizar el trabajo de Sanger como herramienta conceptual y práctica para su propio trabajo. También se comprometieron activamente con el propio Singer, intentando ganárselo para su causa. Desde su punto de vista, Sanger inventó las técnicas y ellos avistaron los problemas para los que éstas podían ser útilmente aplicadas. En otras palabras, Sanger necesitaba y merecía ser reeducado en genética ${ }^{69}$. A mediados de los 50, Crick y Brenner estaban particularmente interesados en las técnicas autoradiográficas para la identificación de proteínas que Sanger estaba desarrollando. Esta técnica era mucho más sensible que otros métodos cromatográficos, y Crick y Brenner estaban ansiosos por adoptarla para sus experimentos con fagos El mismo Sanger estaba trabajando con secciones de oviductos que incubaba para obtener la ovalbúmina marcada. Éste era un procedimiento bastante largo y laborioso. Ya en una carta fechada en octubre de 1956, Crick escribió a Brenner que por aquel entonces se encontraba todavía en Johannesburgo: "Le hablé con énfasis a Fred [Sanger] sobre lo extremadamente favorable que podría ser el sistema de fagos para este método... Pareció muy interesado" ${ }^{70}$. Una vez en Cambridge, Brenner visitaba a Sanger a menudo en su laboratorio para aprender sus técnicas y hablar con él ${ }^{71}$. 
En el otoño de 1957, se organizaron una serie de conferencias sobre genética en casa de Crick. El mismo Crick se refería a estas conferencias con el nombre de "tutorías", organizadas para Sanger y su grupo, quienes expresaron su deseo de aprender genética ${ }^{72}$. La versión de Brenner es bastante distinta. Según él, estas conferencias no fueron organizadas específicamente para el grupo de Sanger, aunque Sanger asistiera al menos una vez, sino más bien para el gran grupo de visitantes que trabajaban con genes y síntesis de proteínas, reunidos en Cambridge en aquel año. Aparte de Benzer y Streisinger, también Sewel Champe, un estudiante de Benzer, Mahlon Hoagland, Renato Dulbecco y John Littlefield formaban parte del grupo ${ }^{73}$. En cuanto a Sanger, ha olvidado ya todo lo relativo a estas conferencias.

No obstante, en los años 1959 y 1960, los experimentos de Brenner con proteínas de fago marcadas están documentados en los cuadernos de Sanger. Según Sanger, su asistente, Biddy Segall, había hecho experimentos previos pero no se encontraron sus cuadernos. Estos experimentos eran sobre mutantes amber del fago T4. Estos mutantes, que crecían solamente en las cepas de la bacteria E. Coli $B$, resultaron tener el efecto de terminar la cadena de polipéptidos de manera que sólo se producían fragmentos de la proteína principal, codificada por el gen afectado. Brenner prosiguió con esta línea de investigación cuando ya hacía tiempo que Sanger la había abandonado. Examinando las marcas de los diferentes mutantes, sus colaboradores y él fueron capaces de ordenar los fragmentos de acuerdo a su longitud. El orden descubierto correspondía al orden de la mutación en el mapa genético. Establecieron entonces que el gen y la proteína eran colineales ${ }^{74}$.

El trabajo de Ingram y Brenner convirtió la secuenciación de proteínas en una poderosa herramienta para la genética molecular. La conexión de técnicas bioquímicas y genéticas hecha en el laboratorio de Cambridge llegó a ser una atracción principal para una joven generación de biólogos moleculares. En aquel momento, el grupo de Sanger del departamento de Bioquímica se unió al de los cristalógrafos y genetistas moleculares en el nuevo Laboratorio de Biología Molecular. ¿Se habían convertido los químicos de proteínas 
Secuencias, conformación, información...

en biólogos moleculares? No, según Sanger. Permítaseme examinar cómo se relacionaban las interacciones en el nivel experimental con los desarrollos institucionales y disciplinares.

\section{Redes y Disciplinas}

Las múltiples maneras en las que Kendrew, Edmundson, Crick, Brenner y Sanger interaccionaban entre sí pueden llevarnos a pensar que era una opción obvia, la de incluir al grupo de secuenciación de Sanger en los nuevos planes para un laboratorio de Biología Molecular, las negociaciones sobre el cual con el Medical Research Council y la Universidad empezaron en 1957. De hecho, ésta es la explicación que recibí, generalmente, cuando hablé con los protagonistas. Aunque una construcción más detallada de los diversos acontecimientos ofrece un panorama de eventos mucho más complejo.

La primera razón para considerar el establecimiento de un nuevo laboratorio era una muy práctica: la MRC-Unit necesitaba más espacio. Se presentaron numerosas sugerencias y esquemas diferentes. Abarcaban desde el plan para albergar la unidad de Perutz junto con todos los otros grupos de investigación de Cambridge financiados por el Medical Research Council en un mismo edificio a la separación y dispersión del grupo de Cavendish. Una solución posible era que el propio Crick se presentara a la cátedra de genética de Cambridge, que R. A. Fisher había dejado vacante. No obstante, el comité elegido decidió aparentemente que Crick no sabía nada sobre genética ${ }^{75}$. Éste y otros intentos fallidos reforzaron la convicción de que la mejor solución era la de un nuevo laboratorio independiente.

Los documentos que finalmente discutían la opción de un nuevo laboratorio, incluyendo el grupo de Sanger, fueron, en primera instancia, documentos políticos. Sólo en esta ocasión fue usado el término "biología molecular" para nombrar la nueva empresa. Era definido de tal manera para que cubriera los planes de investigación de las personas implicadas en el plan ${ }^{76}$. El laboratorio, sin embargo, era 
una federación. Las colaboraciones entre las tres divisiones de estudios estructurales, genética molecular y química de proteínas se desarrollaron lentamente, de forma individual y no necesariamente como aparecían diseñadas en los documentos oficiales. Consideremos, por un momento, el caso de Sanger. En un documento presentado al comité de la Universidad para discutir sobre el nuevo laboratorio, Sanger expuso que los secuenciadores y cristalógrafos de proteínas eran compañeros obvios de trabajo en un proyecto común de laboratorio. El problema de la estructura de proteínas, explicó, podía estar dividido en dos partes: la secuencia de aminoácidos y el plegamiento tridimensional de la cadena de polipéptidos. Concluyó: "Nosotros estudiamos lo primero; Perutz y Kendrew, lo segundo" ${ }^{77}$. Sin embargo, Sanger nunca interactuó personalmente con los cristalógrafos ${ }^{78}$. Aun cuando intentó dar cuenta sobre su posterior "conversión" de la secuenciación de proteínas a la de ácidos nucleicos no dejó de referirse a "la atmósfera" del Laboratorio de Biología Molecular, y a la influencia de estar rodeado de investigadores como Francis Crick y John Smith, siendo este último el experto en ácidos nucleicos del nuevo laboratorio ${ }^{79}$.

De igual interés son los diferentes testimonios ofrecidos por los protagonistas de los hechos que condujeron a la creación del Laboratory of Molecular Biology. Mientras que Crick, Brenner, Kendrew y Perutz propagaban la biología molecular como un nuevo modo de practicar la biología, para Sanger el nombre "biología molecular" debía inventarse al existir ya un laboratorio de bioquímica en Cambridge. Desde su punto de vista, él siempre continuó con la bioquímica. Consideró a Crick como el primer bioquímico teórico. Según Sanger, quien a su vez era un experimentador agudo, las teorías de Crick eran importantes al sintetizar los resultados y propagar ciertas perspectivas, pero no eran directamente relevantes para el trabajo práctico ${ }^{80}$.

Aquí Sanger habla claramente desde la posición aventajada de una disciplina bien establecida a la que pertenecía por formación y para renunciar a cuya lealtad carecía de motivos. Pero entre otras, la historia triunfal del Laboratory of Molecular Biology en Cambridge, al que el grupo de Sanger contribuyó decisivamente, modificaría el equilibrio 
Secuencias, conformación, información...

de poderes. Los bioquímicos en Cambridge se resentían del desarrollo del laboratorio - se quejaban-porque atraía a sus mejores investigadores, sin contribuir a la docencia universitaria.

La disputa entre biólogos moleculares y bioquímicos pronto cruzó los límites locales. En 1966, el «informe Kendrew" elaborado por el Working Group of Scientific Policy on Molecular Biology, organizado por el recién formado Council of Scientific Policy, sugirió reagrupar la enseñanza y la investigación en las ciencias biológicas introduciendo una aproximación molecular. La Biochemical Society replicó con un contramanifiesto firmado por Hans Krebs, por el cual reclamaba sus derechos de permanencia en ese mismo territorio ${ }^{81}$. En estas disputas estaban en juego demandas de recursos públicos y el reclutamiento de la próxima generación de científicos. Estas cuestiones son de vital importancia para el establecimiento de una disciplina científica. Es una cuestión a debatir si los biólogos moleculares fueron de verdad los triunfadores en este juego, especialmente en Cambridge, donde, hasta hoy no hay ni un jefe de departamento, ni un departamento en sí de biología molecular. Las disciplinas biológicas tradicionales, incluyendo la de los bioquímicos, sin embargo, respondieron a la presión de "molecularizarse", importando nuevas prácticas de investigación e introduciendo cursos de biología molecular en sus enseñanzas.

En Cambridge, la biología molecular surgió de la alianza entre cristalógrafos de proteínas, genéticos moleculares y químicos de proteínas. Las colaboraciones prácticas entre científicos de diferentes culturas de investigación estuvieron acompañadas de negociaciones institucionales y disciplinarias. El análisis detallado sobre la forma en la que la secuenciación de proteínas se usó y sobre la cooptación de Sanger para el plan del nuevo laboratorio muestran que ambos niveles de interacciones contribuyeron de forma compleja a la construcción de un nuevo campo científico. Sanger, que incluso se hubiera unido al Laboratory of Molecular Biology, mantuvo su identidad disciplinaria como bioquímico o, más precisamente, no manifestó ninguna distinción entre biología molecular y bioquímica. El que su trabajo pudiera ser usado para construir reivindicaciones disciplinarias 
opuestas resalta, una vez más, que las prácticas experimentales y las identidades disciplinarias carecen de relación unívoca. Ambas son prácticas disciplinarias y su interrelación requiere una investigación detallada para cada caso particular.

\section{Agradecimientos}

Agradezco enormemente la cooperación de la señora McAdam Clark del Archivo del MCR, y de Sidney Brenner, Francis Crick, Brian Hartley, Vernon Ingram, John Kendrew y Fred Sanger, quienes aceptaron ser entrevistados y me dieron permiso para consultar material no publicado. También deseo dar las gracias a Jean-Paul Gaudillière y a Lily Kay por sus comentarios y extensas discusiones. Este artículo forma parte de un proyecto más amplio sobre la historia de la biología molecular en la Gran Bretaña de la posguerra, dotado de una subvención de la Fundación Wellcome.

\section{Notas}

1 Entre otras véanse: Biochemistry, "Molecular Biology" and the Biological Sciences. Report of a Subcommittee of the Biochemical Society on the Working Group on Molecular Biology ("Kendrew Report") and the Present State of Biological Sciences in this Country, with Particular Reference to Biochemistry (Biochemical Society, London, 1969); GoDDwIN, T. W.: British Biochemistry Past and Present, Biochemical Society Symposium No. 30 held in London, December 1969 (Academic Press, London and New York, 1970), especialmente "Chairman Introduction" de DAvidson, J. N., pp. 3-4; CHARGAFF, E.: "The Tower of Babel", Nature 248 (1974), 776-797; COHEN, S. S.: "The Origins of Molecular Biology", Science 187 (1975), 827-830 y "The Biochemical Origins of Molecular Biology Introduction", Trends in the Biochemical Sciences 9 (1984), 334-336; The Origins of Modern Biochemistry. A Retrospect on Proteins. Annals of the New York Academy of Science 325 (1979); Fruton J. S.: A Skeptical Biochemist (Harvard University Press, Cambridge, Mass, 1992), especialmente pp. 195-214.

2 Véanse Olby, R.: "Biochemical Origins of Molecular Biology", Trends in the Biochemical Sciences 11 (1986), 303-305; MORGAN, N., OLBY, R.: "Practising without a License: Discipline Identity in Biochemistry and Molecular Biology", (artículo no publicado); ABIR-AM, P. G.: "The 
Secuencias, conformación, información...

Politics of Macromolecules. Molecular Biologists, Biochemists, and Rhetoric", Osiris 7 (1992), 210-237.

3 Veánse las declaraciones de Monod y Brenner en Judson, H. F.: The Eighth Day of Creation. Makers of the Revolution in Biology (Jonathan Cape, London, 1979), pp. 213 y 231; entrevista con S. Brenner de julio de 1992, en Cambridge; entrevista con F. Crick del 25 de mayo de 1993, en Cambridge. Sorprendentemente, Cohen, al reclamar un lugar para la bioquímica en la historia de la biología molecular, no hizo mención a la secuenciación de proteínas entre las técnicas con las que los bioquímicos habían contribuido al desarrollo del campo; véase Cohen, "Biochemical Origins".

4 Por ejemplo, CricK, F.: "On Protein Synthesis", en The Biological Replication of Macromolecules. Symposia of the Society of Experimental Biology XII (Cambridge University Press, Cambridge, 1958), p. 158.

5 Morgan, Olby: "Practising without a License", p. 23.

6 Véase, Perutz, M.: "The Birth of Molecular Biology", New Scientist, 21 May 1987, p. 40.

7 Latour, B.: Science in Action. How to Follow Scientists and Engineers through Society (Harvard University Press, Cambridge, Mass, 1987), pp. 150 y 245.

8 SANGER, F.: “Sequences, Sequences and Sequences", Annual Review of Biochemistry 57 (1988), 1-28, en la página 4 Sanger aludía al cristalógrafo de rayos X Willian Astbury como el principal impulsor de la estequiometría y a la teoría de Max Bergmann y Carl Niemann como la hipótesis más popular de la estructura de proteínas en aquellos días. "Bill" Pirie y Albert Neuberger, con quien Sanger estudió como doctorando, habían cuestionado la hipótesis de Bergmann-Niemann. Según Sanger un resultado de la teoría fue que estimuló el interés por el análisis de aminoácidos (véase ibid.). Sobre él trabajos previos sobre proteínas basados en la noción de la secuencia como un determinante de la especificidad biológica, ver OLBY, R.: "Historical Aspects of Protein Structure" (texto mecanografiado en 1985) y The Path to the Double Helix. The Discovery of DNA (Dover Publications, New York, 1994), pp. XXV, y 74 y siguientes.

9 Además, Sanger era objetor de conciencia y había sido declarado exento del servicio militar; véase idib., p. 2.

10 Entre ellos estaban Kenneth Bailey, Ernst Frank Williams, Maurice William Rees, George Roland Tristram y Herbert Taylor Macpherson.

11 Chibnall, A. C.: "Amino-Acids Analisys and the Structure of Proteins", Proceedings of the Royal Society London, Series B, 131 (1942) 136-160, en la p. 155. En la misma conferencia Chibnall puso en duda la hipótesis de Bergmann-Niemann basándose en sus precisos análisis de aminoácidos.

12 Archivo de Chibnall, archivadores B20 y B21, archivos de la Universidad, Biblioteca de la Universidad de Cambridge, Inglaterra. Eli Lilly subvencionó las investigaciones de Chibnall sobre la insulina desde 1951 hasta 1958, con sólo una corta interrupción.

13 Fox, S. W.: “Terminal Amino Acids in Peptides and Proteins" Advances in Protein Chemistry 2 (1945), 155-177. 
14 Los relatos de Chibnall y Sanger difieren ligeramente. Para la versión de Chibnall véaser Chibnall, A. C.: Early Days in Biochemistry (Biochemical Society, London, 1987), p. 31-32. Para los comentarios de Sanger al informe de Chibnall véase FruToN, J. S.: A Skeptical Biochemist (Harvard University Press, Cambridge, Mass, 1992), p. 36, nota 52.

15 Véase también OlBY, R.: "The Recasting of the Sciences: The Case of Molecular Biology" en BATTIMeli, G.; MARIA, M. de; Rossi, A. (eds.), La Ristrutturazione delle scienze tra le due guerre mondiali, II, Roma 1986, pp. 237-247.

16 Véase Martin, A. J. P.; Synge, R. L. M.: “A New Form of Chromatogram Employing Two Liquid Phases", Biochemical Journal 35 (1941), 1.358-1.368 y Gordon, A. H.; MarTin, A. J. P.; Synge, R. L. M.: "Partition Chromatography in the Study of Protein Constituents", Biochemical Journal 37 (1943), 76-86.

17 La historia del desarrollo de la separación cromatográfica es recordada por Martin en su Conferencia del Nobel; véase MARTIN, A. J.: "The Development of Partition Chromatography", en Nobel Lectures including Presentation Speeches and Laureates' Biographies. Chemistry 1942-1962 (Elsevier, Amsterdam/London/New York, 1964), pp. 359-371. Véase también SYNGE, R. L. M.: "Aplications of Partition Chromatography", en ibid., pp. 374-387.

18 Véase Chibnall, A. C.: Early Days, p. 31.

19 SANGER, F.: "The Free Amino Groups of Insulin", Biochemical Journal 39 (1945), 507-515. En una exposición posterior sobre su artículo que llegó a ser una referencia estándar para el método de determinación del grupo terminal, Sanger recordaba que el editor del diario, un distinguido químico orgánico, había retrasado la publicación. Éste requirió que los nuevos dinitrofenil-aminoácidos fueran caracterizados, como es normal, por su punto de fusión y el análisis elemental, mientras que Sanger había vuelto a insistir reiteradamente en su comportamiento cromatográfico; véase SANGER, F.: Current Contents 28/12 (1985), 23. Esta incidencia plantea la dificultad de introducir nuevos métodos analíticos en las prácticas habituales.

20 Sanger, F.: Current Contents 28/12 (1985), 23.

21 SANGer, F.: "The Terminal Peptides of Insulin", Biochemical Journal 45 (1949), 563-74 y SANGER, "Sequences", p. 7.

22 Entrevista con F. Sanger el 25 de marzo de 1993, en Cambridge. En una lectura minuciosa de un artículo de revisión de Fox, en 1945, sobre la determinación del grupo final, confirma el principio de Sanger. Fox enumeraba la determinación de la secuencia de aminoácidos como una de los objetivos propuestos de determinación de aminoácidos terminales. Comentando esos trabajos, Fox argumentó que la solución ideal implicaría "la supresión de aminoácidos terminales de un péptido de cualquier longitud manteniéndose inalterado el péptido restante" (Fox, "Terminal Acids", p. 157). Este enfoque fue seguido por el bioquímico sueco Pehr Edman (véase más adelante).

23 Consden, R.; Gordon, A. H.; Martin, A. J. P.; Srnge, R. L. M.: "Gramicidin S: The Sequence of Amino Acid Residues", Biochemical Jour- 
Secuencias, conformación, información...

nal 41 (1947), 596-602. En la misma época en la que Sanger estaba desarrollando su método de secuenciación, Pehr Edman, que estaba trabajando en la Universidad de Lund, desarrollaba un método de secuenciación basado en la degradación secuencial de la cadena de polipéptido. Edman no estaba en una posición favorable para proseguir su trabajo y la acogida fue lenta. Sin embargo, el método suplantó al método de secuenciación de Sanger (véase más abajo).

24 Sanger fue el primero que introdujo las técnicas de marcage radiactivo de Chris Anfinsen que estaba pasando un año sabático en el laboratorio de Sanger en 1954. Sanger recordó: "Previamente había asumido que los isótopos estaban en el reino de los físicos y que los aparatos y las técnicas estarían fuera de mi alcance. Pero aprendí que éste no era el caso y que ya un número de sutratros radiactivos estaban disponibles" (Sanger, "Sequences", p. 11).

25 EDMAN, P.: "Method for Determination of the Amino Acid Sequence in Peptides", Acta Chemica Scandinavica 4 (1950), 283-293.

26 Sobre el desarrollo de las técnicas de secuenciación de Stein y Moore véase más abajo.

27 HaRTLEY, B. S.: “The Primary structure of Proteins", en Goodwin, T. W. (ed.), British Biochemistry Past and Present. Biochemical Society Symposium No. 30 held in London, December 1969 (Academic Press, London/New York, 1970), pp. 29-41. Pero en aquel tiempo Hartley se había trasladado con Sanger del Departamento de Bioquímica al nuevo Laboratorio de Biología Molecular de Cambridge. Sobre la implicación disciplinaria de su traslado véase más adelante.

28 Véase entrevista con B. Hartley el 28 de septiembre de 1992, en Elsworth.

29 En el curso de sus estudios de química de proteínas, Hartley desarrolló también nuevas líneas de investigación. El eligió quimotripsina, un enzima pancreático comercialmente disponible, para su investigación básica y publicó la secuencia completa de la proteína en 1964. Pero en ese tiempo su principal interés había pasado de la función de la enzima a los estudios evolutivos. Comparando las secuencias de enzimas pancreáticas diferentes él podría mostrar que mientras quimotripsina, tripsina y elastina tenían una actividad biológica diferente, presentaban no obstante una secuencia similar. Hartley dedujo que habían evolucionado de un antepasado común y procedió a desarrollar modelos genéticos para estudiar la historia evolutiva de las proteínas. Véase HARTLEY, B. S.: "Enzymes are Proteins", Advancement of Science 1996, 47-54. Un mecanismo de reacción para la quimotripsina fue sugerido sólo cinco años más tarde a partir de un modelo tridimensional de la molécula que daba cabida a los datos de la secuenciación y de los rayos X; véanse Blow, D. M.; Birktoft, J. J.; Hartley, B. S.: "Role of a Buried Acid Group in the Mechanism of Action of Chymotrypsin", Nature 221 (1969), 337-340. Sobre las interacciones entre químicos de proteínas y cristalógrafos de proteínas véase la próxima sección. Especialmente sobre la colaboración entre Hartley y Blow de su trabajo sobre quimotripsina véase también Chadarevian, S.: "Architektur der Proteine. Strukturforschung am Laboratory of Molecular Biology in Cambridge", en HAGNER, 


\section{Soraya de Chadarevian}

M; RHeinberger, H. J. (eds): Experimentalsysteme in den biologischmedizinischen Wissenschaften: Objekte, Differenzen, Konjunkturen (Akademie Verlag, Berlin, 1994), pp. 181-200.

30 A principios de los años cincuenta, Vicent Du Vigneaud y sus colaboradores, que trabajaban en el Cornell University Medical College, intentaron con éxito la síntesis de la oxitocina polipéptida, la hormona de la contracción uterina de la glándula pituitaria, dando prueba de la estructura que habían determinado anteriormente. Era la primera síntesis de una proteína como hormona y ganó el premio Nobel Du Vigneaud en 1955; véase DU VignEAUD, V.: "A trail of Sulfur research: From Insulin to Oxytoxin", en Nobel Lectures. Chemistry 1942-1962 (Elsevier, Amsterdam/London/New York, 1964), pp. 446-465.

31 Entrevista con J. Kendrew, el 14 de julio de 1993 en Cambridge.

32 Sobre el "problema de fase" y su solución véase GREEN, D. W.; INGRAM, V.; PERUTZ, M. F.: "The Structure of Haemoglobin IV. Sign Determination by the Isomorphous Replacement Method". Proceedings of the Royal Society, A. 225 (1954), 287-329.

33 Kendrew había encontrado la carne de cachalote para sus experimentos en la Low Temperature Research Station en Cambridge donde, durante la guerra, se investigó la posibilidad de usar la carne de cachalote como suplemento de la carne de carnicería. La carne era negra, indicando un alto contenido de mioglobina. Más tarde, lotes de carne de cachalote fueron enviados a Kendrew por avión desde Lima donde la carne podía ser comprada en el supermercado; véase entrevista con J. Kendrew, el 18 de marzo de 1993, en Linton.

34 BERnAL, J. D.: “X-Ray Evidence for the Structure of Protein Molecules", en SvedBerg ET AL. T. : "A Discussion on the Protein Molecule", Proceedings of the Royal Society of London B, 127 (1939), 1-79, en la p. 38. El congreso de la Royal Society contó con la participación de químico-físicos, químicos de coloides, bioquímicos y cristalógrafos de rayos $\mathrm{X}$. Revela la importancia atribuida a este tema e ilustra el intenso intercambio entre investigadores con diferentes conocimientos disciplinarios que se produjo en aquel tiempo. Sobre el papel de la investigación en proteínas en los años treinta, véase también KAY, L.: The Molecular Vision of Life (Oxford University Press, Oxford/New York, 1993), especialmente pp. 104-120.

35 Entrevista con J. Kendrew, Linton, marzo de 1993.

$36 \mathrm{El}$ propio Sanger fue crítico con los enfoques de Stein y Moore sobre la secuenciación de proteínas que suponía el uso de equipos complejos y de un largo y tedioso trabajo rutinario. Él se ajustó a su propio plan para desarrollar métodos de secuenciación más simples y económicos; véase SANGER, F.: "Memorandum to the Medical Research Council" (Sin fecha, adjunto a una carta de Sanger a Mellanby, 26 June 1957), p. 2; MCR Archive, London, Archivo E 242/109, Vol. I.

37 Carta del 2 de noviembre de 1955 de Kendrew a Moore y Stein. Archivo Kendrew, archivador C.273, Bodleian Library, Oxford.

38 Ibid.

39 Ibid. 
Secuencias, conformación, información...

40 LindLey, H.; RolletT, J. S.: “An Investigation of Insulin Structure by Model Building Techniques", Biochemica et Biophysica Acta 18 (1955), 183-193. Lindley estaba de permiso de la Wool Textile Research Laboratories en Melburne, mientras que Rollett estaba en el Laboratory of Chemical Crystallography en el University Museum en Oxford, Inglaterra.

41 La idea de que los genes determinaban las secuencias de los aminoácidos de las proteínas fue retomada por Kendrew del trabajo sobre hemoglobina de células falciformes llevado a cabo por Vernon Ingram en el mismo laboratorio de Cambridge. Para más detalles sobre las investigaciones de Ingram véase más adelante.

42 KendREw, J. C.: "Myoglobin and the Structure of Proteins", en Nobel Lectures, Including Presentation Speeches and Laureates'Biographies. Chemistry 1942-1962 (Elsevier, Amsterdam/London/New York, 1964), 676700 , en la p. 696.

43 Carta del 2 de noviembre de 1955 de Kendrew a Moore y Stein, Archivo Kendrew, archivador C.273, Bodleian Library, Oxford.

44 Carta del 29 de noviembre de 1955 de Moore a Kendrew. Archivo Kendrew, archivador C.273, Bodleian Library, Oxford.

45 Carta del 21 de diciembre de 1955 de Kendrew a Moore. Archivo Kendrew, archivador C.273, Bodleian Library, Oxford.

46 Carta del 20 de marzo de 1956 de Moore a Kendrew. Archivo Kendrew, archivador C.273, Bodleian Library, Oxford.

47 En 1962, cuando la Unit se trasladó del Cavendish al nuevo Laboratory of Molecular Biology, Edmundson, aún vinculado al grupo de cristalografía de rayos-X, tenía esperanzas de ser asignado a la división de química de proteínas, i.e. con el grupo de Sanger, quien se había unido al laboratorio. Aun así la división no estuvo de acuerdo en dar espacio a Edmundson y a sus analizadores de aminoácidos que habían sido embarcados en América. Él finalmente terminó en la división de genetistas moleculares donde algunos investigadores habían comenzado a usar técnicas de secuenciación (véase más abajo). En algún sentido este episodio banal indica los problemas de la construcción de un puente entre diferentes culturas de investigación en instituciones innovadoras como el Laboratory of Molecular Biology que estaba diseñado para fomentar la colaboración.

48 Kendrew, J. et al.: "A Three-Dimensional Model of the Myoglobin Molecule Obtained by X-Ray Analysis", Nature 181 (1958), 662-666.

49 Ibid., p. 665.

50 Dr. NoRTON: "Visit to the Molecular Biology Research Unit, Cambridge, 2nd December 1957" (informe interno no publicado, MRC Archive, London, archivo E243/29).

51 Véase Wilkes, M. W.: Memoirs of a Computer Pioneer (MIT Press, Cambridge, Mass., 1985), p. 192. Sobre el trabajo implicado en el análisis de 2 Angstrom de la mioglobina véase Dickerson, R. E.: “A little Ancient History", Protein Science 1 (1992), 182-186.

52 Kendrew, J. et al.: "A Partial Determination by X-Ray Methods, and Its Correlation by Chemical Data", Nature 190 (1961), 666-672.

53 Véase Edmundson, A. B.; Hirs, C. H. W.: "The Amino-Acid Sequence of Sperm Whale Myoglobin", Nature 190 (1961), 663-665. 
54 Véase JuDson, Eighth Day, p. 229.

55 CRICK: "On Protein Synthesis", p. 152. Expresada así, la hipótesis de la secuencia podría no haber sido formulada antes de la elucidación de la estructura del ADN en 1953. Aun así Crick mantiene que los resultados de la primera secuenciación de Sanger le sugirieron que los genes determinarían la secuencia de aminoácidos incluso antes de 1953. Véase Crick, F.: What Mad Pursuit. A Personal View of Scientific Discovery (Penguin, London, 1990), p. 36 y la entrevista con Crick el 25 de mayo de 1993, en Cambridge.

56 BRENNER, S.: "On the Impossibility of all Overlapping Triplet Codes in Information Transfer from Nucleic Acids to Proteins", Proceedings of National Academy of Sciences 43 (1957), 687.

57 CRICK: "On Protein Synthesis», en la p. 144. Nótese que ésta era posición muy dura a tomar por alguien como Crick cuya principal formación experimental era en la cristalografía de los rayos X.

58 Ibid., p. 153

59 Ibid.

60 Judson, creo que erróneamente, mantuvo que «lo que Chargaff y Sanger hicieron fue reducir la química [de ácidos nucleicos y proteínas] a la dependencia total de la información" (Judson, Eighth Day, p. 243). Como se demostró anteriormente, para Sanger, en su trabajo sobre la insulina, secuencia significaba estructura, no información.

61 CRICK: «On Protein Synthesis", p. 158.

$62 \mathrm{Me}$ refiero a los genetistas moleculares y no a los biólogos moleculares en este contexto, ya que en Cambridge la genética molecular representaba sólo una división de la gran empresa de la biología molecular que surgió de alianzas entre los cristalógrafos de proteínas, genetistas moleculares y químicos de proteínas. De hecho, la combativa posición de Crick respecto a los bioquímicos no le impidió ni a sus colegas de Cambridge ni a él intentar ganarse a Sanger para unirle a sus planes de un nuevo laboratorio de biología molecular (véase más ābajo). $\mathrm{Cu}$ riosamente, para Kendrew los biólogos moleculares se distinguían de los bioquímicos por su interés en la información y en la configuración; véase KendREW, J. C.: "Information and Conformation in Biology", en Rich, A.; DAvidson, N. (eds.): Structural Chemistry and Molecular Biology, volumen dedicado a Linus Pauling por sus estudiantes, colegas y amigos (W. H. Freeman, San Francisco/London, 1968), pp. 187-197.

63 Watson, J. D.; CRICK, F. H. C.: "Genetical Implications of the Structure of Deoxyribonucleic Acid", Nature 171 (1953), 964-967, en la p. 965 .

64 CRICK, F.: What Mad Pursuit, p. 90 y entrevista con F. Crick, Cambridge, 25 de mayo de 1993. Crick sugirió que habría sido más correcto hablar de clave genética en vez de código genético ya que el código Morse era también una clave, pero él no sabía que en aquel momento no habría sonado tan bien. Brenner señaló que rápidamente se dio cuenta de que estaban hablando de mensajes más que de información, también en la acuñación del término "ARN mensajero" posterior (entrevista con S. Brenner, en julio de 1992 en Cambridge). La exposición 
Secuencias, conformación, información...

del código Morse fue también utilizada por Schrödinger para ilustrar el papel de los genes del desarrollo; véase ScHröDINGER, E.: What is Life? The Physical Aspect of the Living Cell with Mind and Matter \& Autobiographical Sketches (Cambridge University Press, Cambridge, 1992), p. 61. Para una perspectiva histórica sobre el uso del término "información" en las ciencias de la vida, véase Fox-KELLER, E.: "The Body of a New Machine: Situating the Organism Between Telegraphs and Computers" en su Refiguring Life. Metaphors of the Twentieth-Century Biology (Columbia University Press, New York, 1995), pp. 79-118 y KAY, L.: "Who Wrote the Book of Life? Information and Transformation of Molecular Biology, 1945-1955", Science in Contex 8 (1996) (en prensa) y Who Wrote the Book of Life? A History of the Genetic Code (Chicago University Press, Chicago, de próxima publicación 1997/8), capítulos 1 y 2 .

65 Véase CRICK: What Mad Pursuit, pp. 103-105.

66 IngRaM, V. M.: “A Specific Chemical Difference Between the Globins of Normal Human and Sickle-Cell Anaemia Haemoglobin", Nature 178 (1956), 792-794 y "Gene Mutations in Human Haemoglobin: The Chemical Difference Between Normal Human and Sickle-Cell Haemoglobin", Nature 180 (1957), 326-328.

67 CRICK: What Mad Pursuit, p. 106.

68 Véase JuDSON, Eighth Day, p. 332. Sobre experimentos posteriores con el mismo objetivo, véase BRENNER, S.; BARNETT, L.: "Genetic and Chemical Studies on the Head Protein of Bacteriophages T2 and T4", en Brookhaven Symposia in Biology, Vol 12: Structure and Function of Genetic Elements (Brookhaven National Laboratory, Upton, NY, 1959), pp. 86-94.

69 Entrevista con S. Brenner, Cambridge, 30 de junio de 1993. Los primeros contactos entre Crick y Sanger se remontan a principios de los años cincuenta, cuando James Watson estaba en Cambridge. El prrncipal canal de comunicación con Sanger era entonces a través de Herbert Gutfreund del Department of Colloid Science que estaba calculando el peso molecular de la insulina, y de quien Crick y Watson eran amigos. Según recuerda Crick ellos también se aproximaron entonces a Sanger informalmente con la sugerencia de que se trasladara del Biochemistry Departament al Cavendish. Sanger, sin embargo, no estuvo de acuerdo, pensó que se sentiría incómodo en un departamento de física. Así que el grupo de Cavendish reclutó entonces a Vernon Ingram; véase carta del 30 de enero de 1996 de Crick a la autora. Para la decisión posterior de Sanger de negociar con el grupo de Cavendish para un nuevo laboratorio común, véase más abajo.

70 Carta de F. Crick a S. Brenner, del 26 de octubre de 1956, citada por JuDson, Eighth Day, p. 331.

71 Entrevista con S. Brenner, el 30 de junio de 1993, en Cambridge. Según Brenner y Crick, ellos también intentaron interaccionar' con Ernest Gale que estaba trabajando sobre biosíntesis de proteínas en bacterias en el mismo departamento que Sanger. Aun así Gale, aparentemente no se mostró nada interesado y los intentos fueron fallidos (entrevista 
con S. Brenner el 30 de junio de 1993, en Cambridge y con F. Crick el 25 de mayo de 1993, en Cambridge). Sobre Gale ver la contribución de Rheinberger en este mismo número del Journal of the History of Biology.

72 CRICK F.: What Mad Pursuit, p. 106. Como mencioné antes, según Crick los bioquímicos llegaron a estar interesados en la genética siguiendo el trabajo de Ingram sobre el efecto de las mutaciones en la composición de aminoácidos de la hemoglobina.

73 Para los recuerdos de aquel año en Cambridge ver HoAgLAND, M.: Toward the Habit of Truth. A Life in Science (New York/London and Company, 1990), pp. 97-116.

74 Sarabhai, A. S.; StretTon, A. O. W.; Brenner, S.: "Co-Linearity of the Gene with the Polypeptide Chain", Nature 201 (1964), 13-17. Las evidencias sobre la hipótesis de la secuencia se habían obtenido justo antes por Charles Yanofsky y sus colaboradores, quienes estaban trabajando en mutantes de la triptofano sintetasa de la $E$. coli; véase YANOFSKY, C. et al.: "On the Colinearity of Gene Structure and Protein Structure", Proceedings of the National Academy of Science, Washington 51 (1964), 226-272.

75 Entrevista con F. Crick, Cambridge, 25 de mayo de 1993.

76 Aunque el término "biología molecular" estaba circulando desde los últimos años 30, la MRC-Unit for Molecular Biology en Cambridge fue, que yo sepa, la primera institución en adoptar el nombre en 1957. Me refiero más detalladamente a la historia del Laboratory of Molecular Biology en Cambridge en un libro que aparecerá proximamente sobre la biología molecular en la posguerra en Gran Bretaña.

77 «Report to the General Board of their Committee on the future of the MRC Unit of the Molecular Biology and associated matters", General Board Paper 4992, University Archives, University Library, en Cambridge.

78 Lo mismo no es cierto para los miembros más jóvenes de su grupo que, después de algunos años, participaron en proyectos con los cristalógrafos de rayos $\mathrm{X}$.

79 SANGER, "Sequences", p. 14; véase "Frederick Sanger" (Autobiografia) en Les Prix Nobel. Nobel Prizes. Presentations, Biographies, and Lectures (Stockholm 1981), p. 142.

80 Entrevista con F. Sanger, Cambridge, 25 de marzo de 1993 y 10 de octubre de 1994.

81 Council for Scientific Policy, Report of the Working Group on Molecular Biology (Her Majesty's Stationary Office, London, 1968) (Cmnd. 3.675) y Biochemistry, 'Molecular Biology' and the Biological Sciences (véase cita n. ${ }^{2}$ 2). Sobre la historia de los dos informes véase MORGAN, OLBY: "Practising without a License" y ABIR-AM: "The Politics of Macromolecules». El artículo de Abir-Am incluye un breve análisis de las diferentes reacciones de los bioquímicos de Gran Bretaña y América con respecto al ascenso de la biología molecular (véase ibíd. pp. 225-226). 